\title{
Molecular Identification and Characterization of Ileal and Cecal Fungus Communities in Broilers Given Probiotics, Specific Essential Oil Blends, and Under Mixed Eimeria Infection
}

\author{
Michael E. Hume, ${ }^{1}$ Charles A. Hernandez, ${ }^{1}$ Nei A. Barbosa, ${ }^{2,3}$ Nilva K. Sakomura, ${ }^{2}$ \\ Scott E. Dowd, ${ }^{4}$ and Edgar O. Oviedo-Rondón ${ }^{3}$
}

\begin{abstract}
Broiler digestive tract fungal communities have gained far less scrutiny than that given corresponding bacterial communities. Attention given poultry-associated fungi have focused primarily on feed-associated toxinproducers, yeast, and yeast products. The current project focused on the use of pyrosequencing and denaturing gradient gel electrophoresis (DGGE) to identify and monitor broiler digestive fungal communities. Eight different treatments were included. Four controls were an Uninfected-Unmedicated Control, an UnmedicatedInfected Control, the antibiotic bacitracin methylene disalicylate plus the ionophore monensin as Positive Control, and the ionophore monensin alone as a Negative Control. Four treatments were two probiotics (BC-30 and Calsporin) and two specific essential oil blends (Crina Poultry Plus and Crina Poultry AF). All chickens except the Unmedicated-Uninfected Control were given, at 15 days of age, a standard oral Eimeria inoculum of sporulated oocysts. Ileal and cecal digesta were collected at pre-Eimeria infection at 14 days of age and at 7 days post-Eimeria infection at 22 days of age. Extracted cecal DNA was analyzed by pyrosequencing to examine the impact of diet supplements and Eimeria infection on individual constituents in the fungal community, while DGGE was used to compare more qualitative changes in ileal and cecal communities. Pyrosequencing identified three phyla, seven classes, eight orders, 13 families, 17 genera, and 23 fungal species. Ileal and cecal DGGE patterns showed fungal communities were clustered mainly into pre- and post-infection patterns. Post-infection Unmedicated-Uninfected patterns were clustered with pre-infection groups demonstrating a strong effect of Eimeria infection on digestive fungal populations. These combined techniques offered added versatility towards unraveling the effects of enteropathogen infection and performance enhancing feed additives on broiler digestive microflora.
\end{abstract}

\section{Introduction}

$\mathbf{F}$ UNGAL INTERACTION WITHIN the poultry intestine is far less understood and investigated than are digestive bacteria. Digestive bacteria are viewed as integral components of poultry production and as first-line defenders against human foodborne enteropathogen colonization in poultry (Cebra, 1999; Kelly and Conway, 2005). Bacterial formulations have been extensively promoted as performance enhancers and as anti-enteropathogens. Attention given fungi has focused mainly on toxin-producing fungi and yeast. Toxin-producing fungi as feed contaminants can result in harmful effects and decreased performance (Javed et al., 2005; Kumar et al., 2003; Ortatatli et al., 2005). Conversely, yeast and yeast products are promoted for their potential to enhance poultry production and protect against human enteropathogen colonization (Baurhoo et al., 2007; Owens et al., 2008).

Due to their ubiquitous nature, fungal hyphae, mycellia, spores, and their byproducts can be ingested by broilers during preening, feeding, and drinking. Beneficial dietary fungi and byproducts potentially offer nutritive value, stimulate host immunity, and exert selective pressure on digestive

\footnotetext{
${ }^{1}$ Food and Feed Safety Research Unit (FFSRU), Southern Plains Agricultural Research Center (SPARC), Agricultural Research Service (ARS), U.S. Department of Agriculture (USDA), College Station, Texas.

${ }^{2}$ Faculdade de Medicina Veterinária e Zootecnia, Universidade Estadual Paulista, Jaboticabal, Brazil.

${ }^{3}$ Department of Poultry Science, North Carolina State University, Raleigh, North Carolina.

${ }^{4}$ Research and Testing Laboratories, Medical Biofilm Research Institute, Lubbock, Texas.
} 
bacteria resulting in improved production (Buts and De Keyser, 2006; Gao et al., 2008; Willis et al., 2009). Probiotic and prebiotic properties of Saccharomyces spp., Aspergillus spp., and Candida spp. have been reported, and findings have encouraged their inclusion in some food animal and human dietary formulations (Anuradha and Rajeshwari, 2005; Balevi et al., 2009; Biggs and Parsons, 2008; Gao et al., 2008; Lee et al., 2006).

Traditional fungal culturing and isolation techniques can require extended growth periods with highly specific media. The development of molecular techniques has streamlined fungal detection and quantification. Communal DNA or molecular probes can be used to target species as well as to facilitate the monitoring of entire fungal communities (Gharizadeh et al., 2004; Goebes et al., 2007; Griffiths et al., 2006; May et al., 2001; Scupham et al., 2006; Urubschurov et al., 2008). Scupham et al. (2006) estimated that fungi comprise $0-10 \%$, with a median of $2 \%$, of biota associated with murine cecal biofilm, and that fungi sparsely populated digesta outside the ceca. Buts and De Keyser (2006) demonstrated that murine mucosal Saccharomyces boulardii increased levels of digestive enzymes, stimulated immune function, and increased levels of polyamines that stimulate gene expression and protein translation. Urubschurov et al. (2008) suggested diet as the main source of fungi in weaned pigs and the type of feed ingested affects digestive yeast community diversity.

Investigations regarding poultry digestive fungal communities, aside from the toxin-producing varieties, have focused mainly on prebiotic and probiotic applications. Yeast, yeast cell walls, and yeast cell wall-derived mannanoligosaccharides have been exhaustively researched in food animals as anti-enteropathogens and production enhancers. Aspergillus, Candida, and Saccharomyces are routinely given to food animals as probiotics (Anuradha and Rajeshwari, 2005; Balevi et al., 2009). Aside from these beneficial isolates and the vast knowledge base regarding toxigenic fungi, very little is known regarding poultry digestive fungal communities. A major limiting factor has been the difficult and laborious task of conventional culturing. Molecular techniques have been adapted for the use of a single community DNA preparation for differentiation of general and specific bacterial, protozoan, plant, and fungal genetic targets. Sample DNA assayed in the current study was collected during a related study in which we examined the impact of Eimeria infection and treatment with two commercial probiotics and two essential oil blends (EO) to minimize this impact on ileal and cecal bacterial populations (Hume et al., 2011). Mixed Eimeria infection was selected as a model to study intestinal modifications caused by a common pathogen that can cause profound changes in intestinal microbial communities (Hume et al., 2006, 2011; Oviedo-Rondón et al., 2006). Coccidiosis is one of the most endemic enteric diseases in broiler production (Dalloul and Lillehoj, 2005). Pyrosequencing and denaturing gradient gel electrophoresis (DGGE), body weight gain (BWG), and feed conversion (FC) values were employed to examine these effects. In the current study, pyrosequencing and DGGE were applied to community DNA preparations to profile poultry ileal and cecal fungi. As far as the authors could determine, this is the first molecular attempt to elucidate broiler digestive tract fungal populations. The objectives were to identify digestive fungal populations and examine the effects of dietary probiotics and EO, along with a mixed Eimeria infection, on digestive fungal communities. Pyrosequencing was applied to examine the impact of feed additives and Eimeria infection on individual constituents in the fungal community, while DGGE was used for comparison of more gross changes in community constituents.

\section{Methods}

\section{Broiler husbandry}

A total of 384 1-day-old male Ross 708 chickens were randomly placed in 48 floor pens (8/pen) as previously described (Hume et al., 2011). Broilers were reared according to safe practices authorized by the Animal Use Protocol Committee of North Carolina State University.

\section{Diets and treatments}

Eight treatments (Table 1) (Hume et al., 2011) included four controls: Uninfected-Unmedicated (UU), UnmedicatedInfected (UI), the antibiotic bacitracin methylene disalicylate (BMD; Alpharma Inc., Animal Health, Bridgewater, NJ) at $50 \mathrm{~g} /$ ton plus the ionophore monensin at $90 \mathrm{~g} / \mathrm{ton}$ (Coban; Elanco Animal Health Division of Eli Lilly \& Co., Indianapolis, IN) as Positive Control (PC), and Coban as Negative Control (NC). Four treatments included the following feed additives: two probiotics, BC-30 (BC30; Ganeden Biotech, Mayfield Heights, $\mathrm{OH}$ ) and Calsporin (CAL; Quality Technology International, Inc., Elgin, IL); and two specific EO, Crina Poultry Plus (CPP; DSM Nutritional Products, Parsippany, NJ) at 300 ppm and Crina Poultry AF (CPF; DSM Nutritional Products) at $100 \mathrm{ppm}$. The four treatment diets also contained monensin. Birds were fed a balanced diet (NRC, 1994) and water ad libitum (Table 2) (Hume et al., 2011).

\section{Coccidia infection}

All chickens except those in the UU control group were gavaged at 15 days of age to introduce a standard oral Eimeria inoculum $(0.5 \mathrm{~mL} / \mathrm{bird})$ of sporulated oocysts of mixed coccidia species: E. acervulina $\left(2 \times 10^{5} / \mathrm{mL}\right)$, E. maxima $\left(2.5 \times 10^{4} /\right.$ $\mathrm{mL})$, and E. tenella $\left(5 \times 10^{4} / \mathrm{mL}\right)$. The inoculum was provided by Dr. Mark C. Jenkins (Animal Parasitic Diseases Laboratory, ARS, USDA). Oocytes had been determined to be non-resistant to any ionophore. The Eimeria doses selected were observed in previous experiments to cause mild intestinal lesions similar to the ones observed under commercial conditions of broiler production.

\section{Sampling and DNA extraction}

Broilers were sacrificed by cervical dislocation. Ileal and cecal digesta were collected aseptically by excision, and by voiding of contents into sterile sample tubes, from six broilers at pre-Eimeria infection per treatment group at 14 days of age and from six additional broilers post-Eimeria infection per group at 22 days of age. Samples were lyophilized and stored at $-80^{\circ} \mathrm{C}$ until DNA extraction from $0.25 \mathrm{~g}$ each (Hume et al., 2003, 2011).

\section{Pyrosequencing}

Tag-encoded FLX amplicon pyrosequencing (bTEFAP) was performed as described previously using fungal SSU sequencing and primers SSUFungiF 5'TGGAGGGCAAGT 
Table 1. Treatments Groups ${ }^{\mathrm{a}}$

\begin{tabular}{|c|c|c|c|c|}
\hline Treatment & Treatment description & Eubiotic & Ionophore $^{\mathrm{b}}$ & $A G P^{c}$ \\
\hline UU & Unmedicated-Uninfected Control & None & No & No \\
\hline UI & Unmedicated-Infected Control & None & No & No \\
\hline PC & Positive Control & None & Yes & Yes \\
\hline $\mathrm{NC}$ & Negative Control & None & Yes & No \\
\hline BC30 & BC- $-30^{\mathrm{d}}$ & Probiotic & Yes & No \\
\hline CAL & Calsporin $^{\mathrm{e}}$ & Probiotic & Yes & No \\
\hline CPP & Crina Poultry Plus ${ }^{\mathrm{f}} 300 \mathrm{ppm}$ & Essential oil blend & Yes & No \\
\hline $\mathrm{CPF}$ & Crina Poultry AF 100 ppm & Essential oil blend & Yes & No \\
\hline
\end{tabular}

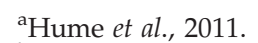

${ }^{\mathrm{b}}$ All treatments and diets contained phytase enzyme (Ronozyme P CT; DSM Nutritional Products, Parsippany, NJ) at $185 \mathrm{~g} /$ ton to provide 925 FYT (phytase units) and ionophore monensin at $90 \mathrm{~g} /$ ton (Coban-90; Elanco Animal Health, Greenfield, IN) in the starter and grower diets (1-35 days of age) of all treatments. Each treatment was assigned to six pens with six male Ross 708 chickens each.

${ }^{\mathrm{C} B a c i t r a c i n}$ methylene disalicylate at $50 \mathrm{~g} /$ ton (Alpharma Inc., Animal Health, Bridgewater, NJ).

${ }^{\mathrm{d}} \mathrm{BC}-30$ is a probiotic containing Bacillus coagulans GBI-30, 6086 at $2.3 \times 10^{7} \mathrm{cfu} / \mathrm{g}$ of feed (Ganeden Biotech, Mayfield Heights, OH).

${ }^{\mathrm{e} C}$ Calsporin contained B. subtilis C-3102 at $3.6 \times 10^{7} \mathrm{cfu} / \mathrm{g}$ of feed (Quality Technology International Inc., Elgin, IL).

${ }^{\mathrm{f}}$ Crina Poultry Plus and Crina Poultry AF are two specific essential oil blends (DSM Nutritional Products, Parsippany, NJ).

CTGGTG'3 and SSUFungiR 5'TCGGCATAGTTTATGGTT AAG'3 (Research and Testing Laboratory, Lubbock, TX) (Dowd et al., 2011). Initial generation of the sequencing library utilized a one-step polymerase chain reaction (PCR) with a total of 30 cycles and a mixture of Hot Start and HotStar highfidelity taq polymerases with average read length of $400 \mathrm{bp}$. Tag-encoded FLX amplicon pyrosequencing analyses utilized Roche 454 FLX instrument with Titanium reagents; titanium procedures were performed at the Research and Testing Laboratory based upon RTL protocols (www.researchandtesting .com).

\section{Fungi diversity data analysis}

Following sequencing, all failed sequence reads, lowquality sequence ends and tags and primers were removed, and sequence collections were depleted of non-fungal ribosome sequences and chimeras using B2C2 (Gontcharova, 2010), as described previously (Bailey et al., 2010). To identify fungi in the remaining sequences, sequences were denoised, assembled into clusters, and queried using a distributed BLASTn .NEt algorithm (Dowd et al., 2005) against a database of high-quality $28 \mathrm{~s}$ fungal sequences derived and curated

Table 2. Percentages of Amplicon Pyrosequences Detected by Fungal Species in Cecal Contents of Broilers at 14 Days of Age

\begin{tabular}{|c|c|c|c|c|c|c|c|c|}
\hline \multirow[b]{2}{*}{ Species } & \multicolumn{8}{|c|}{ Treatment $^{\mathrm{a}}$} \\
\hline & UU & UI & $P C$ & NC & BC30 & $C A L$ & $C P P$ & $C P F$ \\
\hline Alternaria japonica & nd & nd & nd & nd & nd & nd & 25.96 & nd \\
\hline Alternaria sp. & nd & nd & nd & nd & nd & nd & 25.96 & nd \\
\hline Candida khmerensis & nd & nd & nd & nd & nd & nd & nd & 100 \\
\hline Cladosporium sp. & nd & 50.00 & nd & nd & nd & nd & nd & nd \\
\hline Cl. Sphaerospermum ${ }^{\text {b }}$ & nd & 50.00 & nd & nd & nd & nd & nd & nd \\
\hline Clathrospora sp. & nd & nd & nd & nd & nd & nd & 2.01 & nd \\
\hline Embellisia sp. & nd & nd & nd & nd & nd & nd & 25.75 & nd \\
\hline Geosmithia sp. & nd & nd & nd & nd & nd & nd & 1.61 & nd \\
\hline Hypocrea koningii & nd & nd & nd & nd & nd & nd & 3.22 & nd \\
\hline H. pseudokoningii & nd & nd & nd & nd & nd & nd & 1.61 & nd \\
\hline Hypocrea rufa & nd & nd & nd & nd & nd & nd & 1.61 & nd \\
\hline Malassezia restricta & nd & nd & nd & nd & nd & nd & 2.41 & nd \\
\hline Mi. Oncoperae & nd & nd & nd & nd & nd & nd & 0.20 & nd \\
\hline My. Cinctum ${ }^{\mathrm{b}}$ & nd & nd & nd & nd & nd & nd & 1.61 & nd \\
\hline Nomuraea rileyi & nd & nd & nd & nd & nd & nd & 1.61 & nd \\
\hline P. adametzioides ${ }^{\mathrm{b}}$ & nd & nd & nd & nd & nd & nd & 0.60 & nd \\
\hline Penicillium charlesii & nd & nd & nd & nd & nd & nd & 0.60 & nd \\
\hline Trema sp. & nd & nd & nd & nd & nd & nd & 0.40 & nd \\
\hline Ulocladium botrytis & nd & nd & nd & nd & nd & nd & 3.22 & nd \\
\hline V. incurvum ${ }^{\mathrm{b}}$ & nd & nd & nd & nd & nd & nd & 1.61 & nd \\
\hline
\end{tabular}

aTreatment: UU, Unmedicated-Uninfected Control; UI, Unmedicated-Infected Control; PC, Positive Control; NC, Negative Control; BC30, BC-30 Probiotic; CAL, Calsporin Probiotic; CPP, Crina Poultry Plus 300 ppm; CPF, Crina Poultry AF 100 ppm.

${ }^{\mathrm{b}} \mathrm{Cl}$. Sphaerospermum, Cladosporium sphaerospermum; H. pseudokoningii, Hypocrea pseudokoningii; Mi. oncoperae, Microhilum oncoperae; My. Cinctum, Myrothecium cinctum; Penicillium adametzioides, Penicillium adametzioides; V. incuroum, Verticillium incurvum. nd, Not detected. 
monthly from National Center for Biotechnology Information (NCBI). Database sequences were characterized as high quality based upon similar criteria utilized by RDP ver 9 (Cole et al., 2009). Using a .NET and C\# analysis pipeline, the resulting BLASTn outputs were compiled and were validated using taxonomic distance methods, and data reduction analysis was performed as described previously (Bailey et al., 2010).

\section{Fungal identification}

Based upon the above BLASTn-derived sequence identity (percent of total length query sequence which aligns with a given database sequence) and validated using taxonomic distance methods, the fungi were classified at the appropriate taxonomic levels based upon the following criteria. Sequences with identity scores, to known or well-characterized $28 \mathrm{~S}$ sequences, greater than $97 \%$ identity ( $<3 \%$ divergence) were resolved at the species level, between $95 \%$ and $97 \%$ at the genus level, between $90 \%$ and $95 \%$ at the family level, between $85 \%$ and $90 \%$ at the order level, between $80 \%$ and $85 \%$ at the class level, and between $77 \%$ and $80 \%$ at the phyla level. After resolving based upon these parameters, the percentage of each fungal ID was individually analyzed for each sample providing relative abundance information within and among the individual samples based upon relative numbers of reads within each. Evaluations presented at each taxonomic level, including percentage compilations, represent all sequences resolved to their primary identification or their closest relative (Bailey et al., 2010).

\section{Denaturing gradient gel electrophoresis}

Amplification targeted a highly variable region of fungal $28 \mathrm{~S}$ ribosomal DNA and was run according to Sandhu et al. (1995). Template DNA was added to Ex Taq Hot Start Mix (TaKaRa Bio USA, Mountain View, CA, a division of Clontech Laboratories, Inc., Madison, WI; vendor Fisher Scientific, Pittsburg, PA) containing 20 pmol of each universal fungal primers U1 (5'-GTGAAATTGTTGA AAGGGAA-3') and U2 (5'-CGCCCGCCGCGCGCGGCGGGCGGGGCGGGGGGT GAAATTGTTGAAAGGGAA-3') with a 31-bp G-C clamp (underlined) (Xin-Yu et al., 2010). Reactions were run in a
PTC-200 Peltier Thermal Cycler (MJ Research, Inc., Waltham, MA) with the following program (Xin-Yu et al., 2010): (1) denaturation at $95^{\circ} \mathrm{C}, 1 \mathrm{~min}$; (2) denaturation at $95^{\circ} \mathrm{C}, 45 \mathrm{sec}$; (3) annealing at $55^{\circ} \mathrm{C}, 30 \mathrm{sec}$; (4) extension at $72^{\circ} \mathrm{C}, 45 \mathrm{sec}$; (5) repeat steps 2-4 for 34 cycles; (6) final extension at $72^{\circ} \mathrm{C}$, $10 \mathrm{~min}$; and (7) maintain at $4^{\circ} \mathrm{C}$. Amplicons were confirmed by agarose gel electrophoresis ( $2 \%$ 48-well E-gel [Invitrogen, Carlsbad, CA], 60 V, $20 \mathrm{~min}$ ). Runs for DGGE were conducted on $8 \%$ polyacrylamide gels (acrylamide-bisacrylamide ratio, 37.5:1; Bio-Rad Laboratories, Richmond, CA) with a $40-60 \%$ urea-deionized formamide gradient $(100 \%$ was $7 \mathrm{M}$ urea and 40\% deionized formamide) (Hume et al., 2003, 2011).

\section{Results}

\section{Pyrosequencing}

Three phyla were identified, with a total of 392 hits, seven classes, eight orders, 13 families, 17 genera, and 23 species. Ascomycota and Basidiomycota were detected in Eimeria preand post-infected broilers, while Microsporidia was detected only in post-infected broilers. Twenty of the 23 total species were detected in pre-infected broilers, with the distribution of detected sequences being limited to three treatment groups: $\mathrm{UU}, \mathrm{CPP}$, and CPF. Seventeen of the 20 species detected in pre-infected broilers came from the group given CPP (Table 2). A Cladosporium sp. and Cladosporium sphaerospermum were detected in UI control broilers, and Candida khmerensis was found in CPF. Those species at greater than $10 \%$ of the detected population were Alternaria japonica, Alternaria sp., Candida kmerensis, Cladosporium sp., Cladosporium sphaerospermum, and Embellisia sp. Only eight species sequences were detected in ceca from post-Eimeria infected broilers (Table 3). Again, detected and identified sequences were seen in three treatment groups: UI control, CAL, and CPP. Seven species sequences were detected at levels $10 \%$ and above: Alternaria japonica, and Alternaria sp., Embellisia sp., Engyodontium album, Malassezia restricia, Systenostrema alba, and Trema sp. Sequences given the identity of known genus and the designation of species refers to a unique species sequence that was identified, but did not match a known fungal species sequence in the data base. A few of the sequences identified have plant, insect, or undomesticated animal disease

Table 3. Percentages of Pyrosequences Detected for Fungal Species in Cecal Contents of Broilers 7 Days After Mixed Eimeria spp. Infection

\begin{tabular}{|c|c|c|c|c|c|c|c|c|}
\hline \multirow[b]{2}{*}{ Species } & \multicolumn{8}{|c|}{ Treatment $^{\mathrm{a}}$} \\
\hline & UU & UI & $P C$ & NC & BC30 & $C A L$ & $C P P$ & $C P F$ \\
\hline Alternaria japonica & nd & nd & nd & nd & nd & nd & 16.7 & nd \\
\hline Alternaria sp. & nd & nd & nd & nd & nd & nd & 16.7 & nd \\
\hline Embellisia sp. & nd & nd & nd & nd & nd & nd & 16.7 & nd \\
\hline E. albumb & nd & nd & nd & nd & nd & 11.1 & nd & nd \\
\hline Malassezia restricta & nd & 52.6 & nd & nd & nd & 88.9 & nd & nd \\
\hline Malassezia sp. & nd & 5.3 & nd & nd & nd & nd & nd & nd \\
\hline Systenostrema alba & nd & 31.6 & nd & nd & nd & nd & 50.0 & nd \\
\hline Trema sp. & nd & 10.5 & nd & nd & nd & nd & nd & nd \\
\hline
\end{tabular}

aTreatment: UU, Unmedicated-Uninfected Control; UI, Unmedicated-Infected Control; PC, Positive Control; NC, Negative Control; BC30, BC-30 Probiotic; CAL, Calsporin Probiotic; CPP, Crina Poultry Plus 300 ppm; CPF, Crina Poultry AF 100 ppm.

${ }^{\mathrm{b}}$ E. album, Engyodontium album.

nd, Not detected. 
potential, but are likely filling vastly different niches in the broiler digestive tract.

\section{Denaturing gradient gel electrophoresis}

Analysis of PCR amplicons on agarose gel revealed positive amplification from only seven DNA samples: ileal UI postEimeria infection, and cecal post-infection UI, PC, CAL, BC30, $\mathrm{CPP}$, and CPF. All other amplicon mixtures (10 $\mu \mathrm{L}$ of each) were subjected to a second PCR to enhance visualization of the sparse results from the primary amplification. The five samples that gave positive results with the first PCR were similarly examined by a second reaction. This second amplification was to determine if any qualitative changes might occur following the first PCR amplification. Resulting band patterns from those reactions were similar to those from the first amplicon patterns.

Ileal Eimeria pre- and post-infection fungal amplicons (Fig. 1) were clustered separately with a $34.6 \%$ SC. Pre-infection patterns, with the exception of $\mathrm{CPF}$, were clustered together with a $77.3 \%$ SC. The pattern for pre-infection CPF was most unlike (18.2\% SC) any pre- and post-infection pattern. Patterns from post-infection ilea shared a $74.1 \%$ SC. The EO groups at pre- and post-infection clustered together with moderate to relatively high \%SC. Clustering of PC with BC30 was seen at pre- and post-infection with greater pattern similarity seen at post-infection.

Similar to arrangements seen in ileal and cecal MC (Fig. 2) were clustered mainly into pre- and post-infection patterns. Pre-infection UU and UI were clustered together and shared a $93 \%$ SC, while UI shared a $95.8 \%$ SC with the two groups given EO. The post-infection UU was clustered with the preinfection groups, but with a very low $43.4 \%$ SC.

\section{Discussion}

In the current study, relative abundance of broiler ileal and cecal fungi were examined following treatment with two commercial probiotics and two EO as feed additives and
Eimeria infection. This current study is a companion to the study in which we examined the effects of treatment and infection on bacterial populations, BWG, and FC (Hume et al., 2011). Twenty-three species sequences were detected in preEimeria-infected chicks at 14 days of age, while only eight were detected 7 days later at post-infection. This decline in species may be related to the maturing of the cecal microflora towards a complement of bacteria more antagonistic to fungi than those found in the younger chicks. Eimeria infections could also reduce microbial diversity in broiler cecal contents (Hume et al., 2011). Additionally, one must always consider potential PCR bias that may be introduced by combinations of template, possible PCR inhibitors co-isolated with template DNA, and reaction mixture components (Wintzingerode et al., 1997; Poltz et al., 1998; Anderson et al., 2003).

The majority of detected fungal species were seen in broilers given Eimeria and no feed additives, and mainly in chickens fed the same basal diet, but with CPP. Components of CPP (i.e., benzoic acid, thymol, eugenol) exhibit in vitro and dose-dependent antibacterial and antifungal properties (Kandil et al., 1994; Vázquez et al., 2001; Cueva et al., 2010). These antibiotic effects of CPP may be suppressing the growth of antagonists that would normally outcompete the detected fungal species. The final effect for the broiler host seems to be positive, since CPP broilers had significantly better feed utilization than UI control broilers up to 14 days of age (Hume et al., 2011). The CPF formulation is similar to CPP, with the exception that CPF does not contain benzoic acid and relatively less CPF (100 vs. 300 ppm) was added to the feed. Groups UU and UI were not feed additives. However, the two Cladosporium spp. were observed in UI at pre-Eimeria infection, but not in UU, when they were essentially the same treatment up to 14 days. The two Malassezia spp., Systenostrema alba, and the Trema sp. detected at post-infection were not evident in UU. These differences may be directly attributed to effects of mixed Eimeria infection. The mixed Eimeria spp. infection used caused mild lesions in the jejunal, ileal, and cecal mucosa, and almost no lesions were observed in the
FIG. 1. Dendrogram of $28 \mathrm{~S}$ rDNA denaturing gradient gel electrophoresis (DGGE) amplicon patterns of ileal fungal contents in broilers at 14 days of age Eimeria spp. pre-infection (Il Pr) and at 22 days of age, 7 days after infection (Il Po). Percentage similarity coefficient (bar) of band patterns is indicated by their grouping on the dendogram. Treatment: UU, Unmedicated-Uninfected Control; UI, Unmedicated-Infected Control; PC, Positive Control; NC, Negative Control; BC30, BC-30 Probiotic; CAL, Calsporin Probiotic; CPP, Crina Poultry Plus; CPF, Crina Poultry AF.

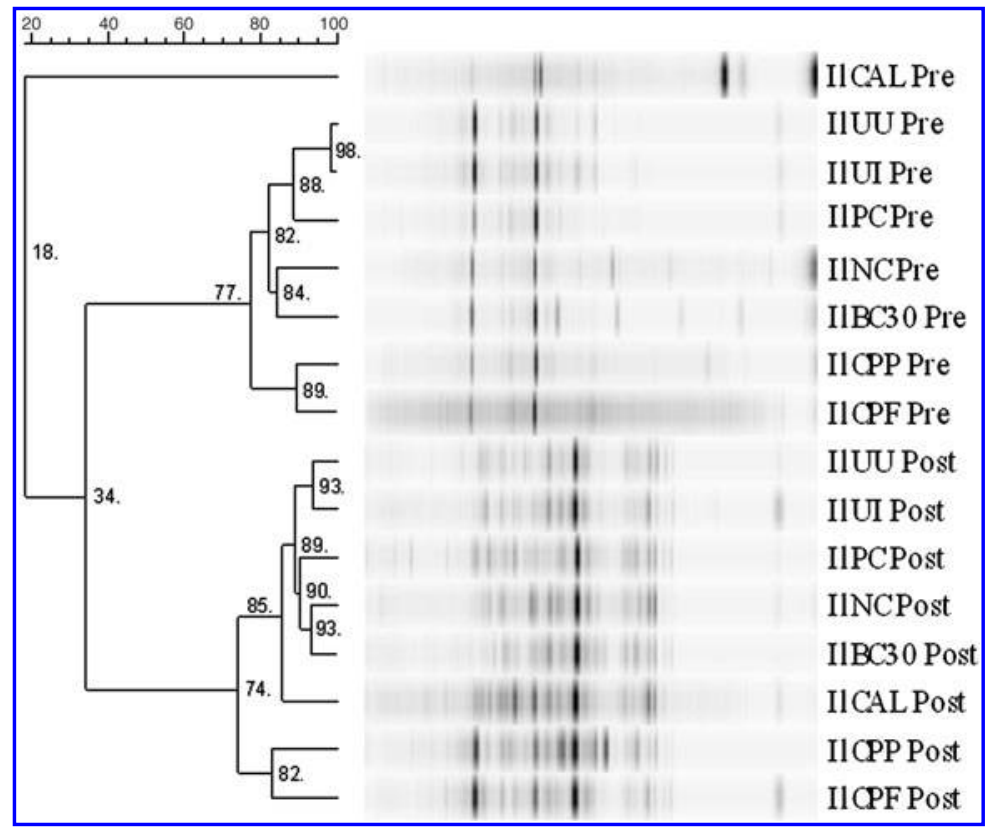




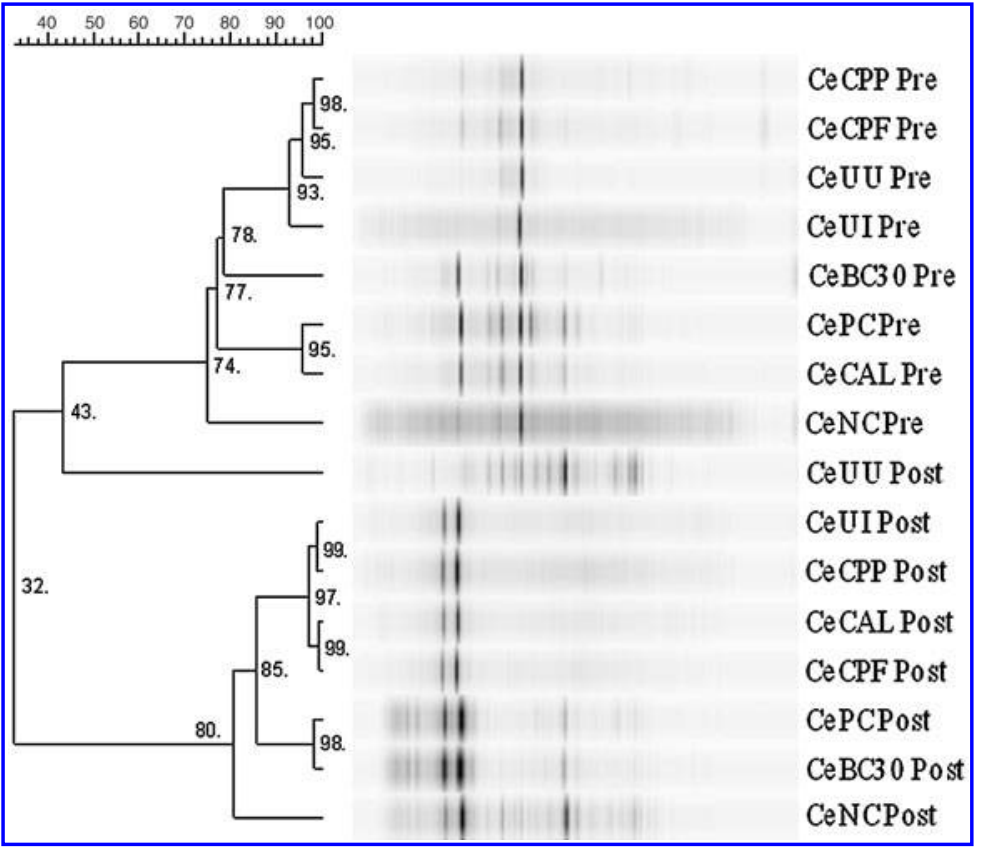

FIG. 2. Dendrogram of $28 \mathrm{~S}$ rDNA denaturing gradient gel electrophoresis (DGGE) amplicon patterns of cecal fungal contents in broilers at 14 days of age Eimeria spp. pre-infection (Il Pr) and at 22 days of age, 7 days after infection (Il Po). Percentage similarity coefficient (bar) of band patterns is indicated by their grouping on the dendogram. Treatment: UU, Unmedicated-Uninfected Control; UI, Unmedicated-Infected Control; PC, Positive Control; NC, Negative Control; BC30, BC-30 Probiotic; CAL, Calsporin Probiotic; CPP, Crina Poultry Plus; CPF, Crina Poultry AF. duodenum. Mucosal lesions indicated changes in intestinal physiology that can be linked to reduction in diversity and number of fungal populations as they were observed in bacterial populations in other studies (Hume et al., 2006, 2011; Oviedo-Rondón et al., 2006).

Broilers fed dietary BC 30 and the two EO treatments had BWG better than broilers in the UI treatment, similar to the PC and NC, but lower than the UU control group (Hume et al., 2011). Feed utilization of the two probiotic treatments and CPF group was similar to UU, control groups PC and NC, and better than UI. Higher numbers of fungal populations did not indicate better feed utilization post-infection. Identifying the treatment attributes eliciting these responses and their implications will require further study.

Pyrosequencing was very sensitive at detecting shifts in individual sequences, whereas DGGE was able to detect qualitative shifts in entire populations. Scupham et al. (2006) estimated the fungal community as a fraction of the total murine cecal biofilm microflora. It was apparent that fungal DNA was present in these broiler digesta. However, target sequence quantity was very low. A subsequent PCR of $10 \mu \mathrm{L}$ of amplicon mixture from the initial amplification was used for samples that did not yield a positive result in the initial PCR. This second PCR gave positive bands on agarose gels for all apparently negative samples and distinct bands following DGGE. Re-amplification can result in PCR artifacts, heteroduplex formation, or bias from low template copy number (Chandler et al., 1997; Thompson et al., 2002; Syvyk et al., 2008). However, the DGGE band patterns were very similar in profile to those seen in the previously positive samples. Additionally, re-amplification of cecal samples that gave positive results in the first PCR resulted in band patterns identical to the first assays.

Ileal and cecal DGGE patterns, respectively, formed two main clusters: pre- and post-Eimeria infection. The fungal cluster pattern somewhat resembles the effect of Eimeria infection exhibited by bacterial clustering (Hume et al., 2006, 2011; Oviedo-Rondón et al., 2006). The effect of Eimeria on cecal fungal communities can be seen with the clustering of post-infection UU with the pre-infection patterns. Common to these groups is that they were not infected with Eimeria. Ileal microbial communities are more transient than cecal fermentative communities. Therefore, far fewer fungi were found in broiler ileal contents than in ceca. Also, due to the expected ileal transience, there would likely be less of an effect of Eimeria infection on ileal than on cecal communities.

The combined techniques of pyrosequencing and DGGE offered added versatility towards unraveling the effects of enteropathogen infection and performance enhancing feed additives on broiler digestive fungal flora. Results show modifications of fungal communities resulting from feed additives prior to infection with a standard mixed Eimeria spp. Nevertheless, none of the feed additives evaluated resulted in modifying the digestive fungal populations to resemble those seen in uninfected broilers post-infection. This result offers preliminary insights into broiler digestive fungal communities, and the effects of pathogen infection and performance enhancing diet supplements on these communities.

\section{Acknowledgments}

Mention of trade names or commercial products in this publication is solely for the purpose of providing specific information and does not imply recommendation or endorsement by the U.S. Department of Agriculture or North Carolina State University.

\section{Disclosure Statement}

No competing financial interests exist.

\section{References}

Anderson IC, Campbell CD, Prosser JI. Potential bias of fungal $18 \mathrm{~S}$ rDNA and internal transcribed spacer polymerase chain reaction primers for estimating fungal biodiversity in soil. Environ Microbiol 2003;5:36-47. 
Anuradha S, Rajeshwari K. Probiotics in health and disease. J Indian Acad Clin Med 2005;6:67-72.

Bailey MT, Dowd SE, Parry NM, Galley JD, Schauer DB, Lyte M. Stressor exposure disrupts commensal microbial populations in the intestines and leads to increased colonization by $\mathrm{Ci}$ trobacter rodentium. Infect Immun 2010;78:1509-1519.

Balevi T, Uçan US, Coşkun B, Kurtoglu V, Cetingül IS. Effect of dietary probiotic on performance and humoral immune response in layer hens. Arch Zootec 2009;12:14-23.

Baurhoo B, Letellier A, Zhao X, Ruiz-Feria CA. Cecal populations of lactobacilli and bifidobacteria and Escherichia coli populations after in vivo Escherichia coli challenge in birds fed diets with purified lignin or mannanoligosaccharides. Poult Sci 2007;86:2509-2516.

Biggs P, Parsons CM. The effects of Grobiotic-P on growth performance, nutrient digestibilities, and cecal microbial populations in young chicks. Poult Sci 2008;87:1796-1803.

Buts JP, De Keyser N. Effects of Saccharomyces boulardii on intestinal mucosa. Dig Dis Sci 2006;51:1485-1492.

Cebra JJ. Influences of microbiota on intestinal immune system development. Am J Clin Nutr 1999;69:1046S-1051S.

Chandler DP, Fredrickson JK, Brockman FJ. Effect of PCR template concentration on the composition and distribution of total community $16 \mathrm{~S}$ rDNA clone libraries. Mol Ecol 1997;6:475-482.

Cole JR, Wang Q, Cardenas E, Fish J, Chai B, Farris RJ, KulamSyed-Mohideen AS, McGarrell DM, Marsh T, Garrity GM, Tiedje JM. The Ribosomal Database Project: Improved alignments and new tools for rRNA analysis. Nucleic Acids Res 2009;37:D141-D145.

Cueva C, Moreno-Arribas MV, Martín-Alvarez PJ, Bills G, Vicente MF, Basilio A, Rivas CL, Requena T, Rodríguez JM, Bartolomé B. Antimicrobial activity of phenolic acids against commensal, probiotic and pathogenic bacteria. Res Microbiol 2010;161:372-382.

Dalloul RA, Lillehoj HS. Recents advances in immunomodulation and vaccination strategies against coccidiosis. Avian Dis 2005;49:1-8.

Dowd SE, Zaragoza J, Rodriguez JR, Oliver MJ, Payton PR. Windows .NET Network Distributed Basic Local Alignment Search Toolkit (W.ND-BLAST). BMC Bioinformatics 2005;6:93.

Dowd SE, Delton Hanson J, Rees E, Wolcott RD, Zischau AM, Sun Y, White J, Smith DM, Kennedy J, Jones CE. Survey of fungi and yeast in polymicrobial infections in chronic wounds. J Wound Care 2011;20:40-47.

Gao J, Zhang HJ, Yu SH, Wu SG, Yoon I, Quigley J, Gao YP, Qi $\mathrm{GH}$. Effects of yeast culture in broiler diets on performance and immunomodulatory functions. Poult Sci 2008;87:13771384.

Gharizadeh B, Norberg E, Löffler J, Jalal S, Tollemar J, Einsele H, Klingspor L, Nyrén P. Identification of medically important fungi by the pyrosequencing technology. Mycoses 2004;47:2933.

Goebes MD, Hildemann LM, Kujundzic E, Hernandez M. Realtime PCR for detection of the Aspergillus genus. I Environ Monit 2007;9:599-560.

Gontcharova V, Youn E, Wolcott RD, Hollister EB, Gentry TJ, Dowd SE. Black Box Chimera Check (B2C2): A Windowsbased software for batch depletion of chimeras from bacterial 16S rRNA Gene Datasets. Open Microbiol J 2010;4:6.

Griffiths LJ, Anyim M, Doffman SR, Wilks M, Millar MR, Agrawal SG. Comparison of DNA extraction methods for Aspergillus fumigatus using real-time PCR. J Med Microbiol 2006;55:1187-1191.
Hume ME, Kubena LF, Edrington TS, Donskey CJ, Moore RW, Ricke SC, Nisbet DJ. Poultry digestive microflora biodiversity as indicated by denaturing gradient gel electrophoresis. Poult Sci 2003;82:1100-1107.

Hume ME, Clemente-Hernández S, Oviedo-Rondón EO. Effects of feed additives and mixed Eimeria spp. infection on intestinal microbial ecology of broilers. Poult Sci 2006;85: 2106-2111.

Hume ME, Barbosa NA, Dowd SE, Sakomura NK, Nalian AG, Martynova-Van Kley A, Oviedo-Rondón EO. Use of pyrosequencing and DGGE to examine the effects of probiotics and $\mathrm{EO}$ on digestive microflora in broilers under mixed $E i$ meria infection. Foodborne Pathogens Dis 2011;8:1159-1167.

Javed T, Bunte RM, Dombrink-Kurtzman MA, Richard JL, Bennett GA, Côté LM, Buck WB. Comparative pathologic changes in broiler chicks on feed amended with Fusarium proliferatum culture material or purified fumonisin B1 and moniliformin. Mycopathologia 2005;159:553-564.

Kandil O, Radwan NM, Hassan AB, Amer AM, el-Banna HA, Amer WM. Extracts and fractions of Thymus capitatus exhibit antimicrobial activities. J Ethnopharmacol 1994;44:19-24.

Kelly D, Conway S. Bacterial modulation of mucosal innate immunity. Mol Immunol 2005;42:895-901.

Kumar A, Jindal N, Shukla CL, Pal Y, Ledoux DR, Rottinghaus GE. Effect of ochratoxin A on Escherichia coli-challenged broiler chicks. Avian Dis 2003;47:415-424.

Lee KW, Lee SK, Lee BD. Aspergillus oryzae as probiotic in poultry-A review. Int J Poul Sci 2006;5:1-3.

May LA, Smiley B, Schmidt MG. Comparative denaturing gradient gel electrophoresis analysis of fungal communities associated with whole plant corn silage. Can J Microbiol 2001;47:829-841.

[NRC] National Research Council. Nutrient Requirements of Poultry, 9th ed. rev. ed. Washington, DC: National Academy Press, 1994.

Ortatatli M, Oğuz H, Hatipoğlu F, Karaman M. Evaluation of pathological changes in broilers during chronic aflatoxin (50 and $100 \mathrm{ppb}$ ) and clinoptilolite exposure. Res Vet Sci 2005;78:61-68.

Oviedo-Rondón EO, Hume ME, Hernández C, Clemente-Hernández S. Intestinal microbial ecology of broilers vaccinated and challenged with mixed Eimeria spp., and supplemented with essential oil blends. Poult Sci 2006;85:854-860.

Owens B, Tucker L, Collins MA, McCracken KJ. Effects of different feed additives alone or in combination on broiler performance, gut microflora and ileal histology. Br Poult Sci 2008;49:202-212.

Poltz MF, Cavanaugh CM. Bias in template-to-product ratios in multitemplate PCR. Appl Environ Microbiol 1998;64:37243730.

Sandhu GS, Kline BC, Stockman L, Roberts GD. Molecular probes for diagnosis of fungal infections. J Clin Microbiol 1995;33:2913-2919.

Scupham AJ, Presley LL, Wei B, Bent E, Griffith N, McPherson M, Zhu F, Oluwadara O, Rao N, Braun J, Borneman J. Abundant and diverse fungal microbiota in the murine intestine. Appl Environ Microbiol 2006;72:793-801.

Syvyk A, Nalian A, Hume M, Martynova-VanKley A. A positive control for detecting heteroduplexes in DGGE for microbial community fingerprinting. Tex J Sci 2008;60:33-44.

Thompson JR, Marcelino LA, Polz MF. Heteroduplexes in mixed-template amplifications: Formation, consequence and elimination by "reconditioning PCR." Nucleic Acids Res 2002;30:2083-2088. 
Urubschurov V, Janczyk P, Pieper R, Souffrant WB. Biological diversity of yeasts in the gastrointestinal tract of weaned piglets kept under different farm conditions. FEMS Yeast Res 2008;8:1349-1356.

Vázquez BI, Fente C, Franco CM, Vázquez MJ, Cepeda A. Inhibitory effects of eugenol and thymol on Penicillium citrinum strains in culture media and cheese. Int J Food Microbiol 2001;67:157-163.

Willis WL, Isikhuemhen OS, Allen JW, Byers A, King K, Thomas C. Utilizing fungus myceliated grain for molt induction and performance in commercial laying hens. Poult Sci 2009;88: 2026-2032.

Wintzingerode FV, Gobel UB, Stackebrandt E. Determination of microbial diversity in environmental samples: Pitfalls of
PCR-based rRNA analysis. FEMS Microbiol Rev 1997; 21:213-229.

Xin-Yu L, Zhen-Cheng S, Xu L, Cheng-Gang Z, Hui-Wen Z. Assessing the effects of acetochlor on soil fungal communities by DGGE and clone library analysis. Ecotoxicology 2010;19: 1111-1116.

Address correspondence to: Michael E. Hume, Ph.D. FFSRU/SPARC/ARS/USDA 2881 FEB Road College Station, TX 77845

E-mail: Michael.Hume@ars.usda.gov 
This article has been cited by:

1. Ryan M. Huebinger, Ming-Mei Liu, Scot E. Dowd, Fernando A. Rivera-Chavez, John Boynton, Curtis Carey, Kenneth Hawkins, Christian T. Minshall, Steven E. Wolf, Joseph P. Minei, Robert C. Barber. 2013. Examination with Next-Generation Sequencing Technology of the Bacterial Microbiota in Bronchoalveolar Lavage Samples after Traumatic Injury. Surgical Infections 14:3, 275-282. [Abstract] [Full Text HTML] [Full Text PDF] [Full Text PDF with Links] 